\title{
Impact of educational status on HIV/AIDS knowledge, attitude and misconceptions among pregnant women
}

\author{
Winifred Aitalegbe OJIEABU ${ }^{1 *}$, M.N. FEMI-OYEWO ${ }^{2}$ and Cyril Iluobe OJIEABU ${ }^{3}$ \\ ${ }^{I}$ Department of Clinical Pharmacy and Biopharmacy, Faculty of Pharmacy, Sagamu, Olabisi Onabanjo \\ University, Ago Iwoye, Ogun State, Nigeria. \\ ${ }^{2}$ Department of Pharmaceutics and Pharmaceutical Technology, Faculty of Pharmacy, Sagamu, Olabisi \\ Onabanjo University, Ago Iwoye, Ogun State, Nigeria. \\ ${ }^{3}$ Department of Microbiology, Faculty of Life Sciences, University of Benin, Benin city, Edo State, Nigeria. \\ *Corresponding author, E-mail: natbelpharmacy@yahoo.com; Tel: 08037126245.
}

\begin{abstract}
The primary objective of this study was to assess the influence of educational level on HIV knowledge, attitude and misperceptions that may act as barriers in HIV prevention. It was a descriptive cross-sectional study conducted among pregnant women who came for antenatal clinic visits in a teaching hospital in Sagamu, a town in Ogun State, Nigeria. The age range of the respondents was 20-59 years. Age range 30-39 years accounted for the highest percentage (53.1\%). Majority (76.7\%) were of monogamous family. While $63 \%$ had tertiary education and above, $29.3 \%$ had secondary, $6.5 \%$ primary and a minor percentage $(1.2 \%)$ had no formal education. Respondents with tertiary educational level had the major percentage (89\%) of those who indicated that HIV/AIDS is caused by virus, highest percentage on the modes of HIV/AIDS prevention (avoid causal sex (77.6\%), highest knowledge of mother to child transmission (during breast feeding (52\%) and a better receptive attitude (willing to care for a HIV positive family member $(87 \%$,) towards people living with HIV/AIDS (PLWHA) as compared to other respondents. Structured education in the form of health talks which could be delivered at their different educational levels should be targeted at pregnant women during clinic hours.
\end{abstract}

() 2012 International Formulae Group. All rights reserved.

Keywords: Educational level, pregnant women, HIV/AIDS knowledge, attitude.

\section{INTRODUCTION}

Since its emergence in 1981, the HIV pandemic has become one of the most serious infectious disease challenges to public health. Entering its' third decade, virtually every country is affected by it. It affects people regardless of gender, geography or sexual orientation. Joint United Nations Program on HIV/AIDS (UNAIDS) estimated 33.4 million people living with HIV globally in 2008 (UNAIDS, 2009). More than two thirds (68\%) of all people who are HIVpositive lived in Sub-Saharan Africa where more than three quarters $(76 \%)$ of all AIDS deaths occurred in 2007 (UNAIDS/WHO, 2007).

In sub-Saharan Africa as a whole, women account for approximately $60 \%$ of estimated HIV infections (UNAIDS, 2008; 
Garcia-Calleja, 2006). According to the technical report from the federal ministry of health, about 3.11 million people are estimated to be living with HIV in Nigeria by the end of 2010 , thereby making about $9 \%$ of the global HIV burden (FMH, 2010). While globally, women constitute $48 \%$ of adults infected with HIV, in Nigeria, they constitute $57 \%$ with new infections occurring in the 15 25 years old age group (UNAIDS, 2006 ; FMH, 2006).

Without effective measures or awareness campaigns to deal with mother-tochild transmission, 390000 out of the global 430000 children newly infected with HIV during 2008 were from sub-Saharan Africa (UNAIDS, 2008). It has been demonstrated that increased knowledge about AIDS is not a predictor for behavioural change 'Onah et al., 2004) although knowledge about the disease is a prerequisite for change (Fawole et al., 1999). Individuals' knowledge of HIV transmission and accurate assessment of their own risk seem to be among the key factors in adoption of safer sexual practices (UNAIDS, 2001).

Health researchers and health care professionals, from both the developed and developing worlds, have long been concerned about the link between health and education (World Bank, 2000). Several different types of biological, psychological and social pathways have been proposed as possibly explaining the association between education and health in general and HIV/AIDS in particular (NIH, 2003). According to research studies, persons with limited health literacy skills are more likely to skip important preventive measures such as mammograms, Pap smears, and flu shots (Scott et al., 2002). They are also more likely to have chronic conditions and are less able to manage them effectively. Studies have found that patients with chronic diseases such as diabetes (Schillinger, 2003) or HIV/AIDS (Kalichman and Rompa, 2000) who have limited health literacy skills have less knowledge of their illness and its management.
In a study to assess the effects of a health education intervention on two nursing groups in Cairo University, Egypt (Eman and Abdelhai, 2011), it was found in general, that the undergraduate nursing group seemed to have exhibited better acquisition of knowledge than the postgraduate after the intervention. Better knowledge detected among the undergraduates was related to more readiness in accepting information and recalling it than the post-graduates who were older and more preoccupied in their work.

Proper knowledge regarding possible routes of transmission is not only crucial for decreasing the infection rate, but it is also important to dispel persistent myths as partial knowledge can further prolong the risk of infection (Babakian et al., 2004). Lack of knowledge and misconception about HIV/AIDS are key factors in the lack of prevention effort and it has been shown that people need a solid factual understanding of HIV and its transmission, access to relevant services, and the confidence and social power to initiate and sustain behaviour change in order to prevent the spread of HIV/AIDS (Cindy et al., 1998).

In contrast to other studies which demonstrated that high education level was associated with higher knowledge scores about HIV (Hayyawi et al., 2010; Eman and Abdelhai, 2011) revealed that better overall knowledge scores were recorded among nursing undergraduates than among postgraduates nurses.

Educational efforts need to be targeted at those who are most misinformed to meet the needs of different populations but despite the fact that better educated respondents (with more years of formal education) had significantly higher knowledge of HIV/AIDS education level was not significantly associated with attitudes towards PLWHA (Tee and Huang, 2009).

The primary objective of this study was to assess the influence of educational level on HIV knowledge, attitude and misperceptions 
that may act as barriers in HIV prevention, among pregnant women.

\section{MATERIALS AND METHODS Study location}

This was a descriptive study carried out at the anti-natal clinic section of the Olabisi Onabanjo University Teaching Hospital, Sagamu, a 241-bed Ogun State government funded tertiary hospital in south-western Nigeria. At the time of the study, the hospital provided health care services in Ogun and neighbouring States and had an average patients' turnover of 974 in-patients and 6,486 out-patients per month.

\section{Study population}

A sample size of 403 pregnant women attending ante-natal clinics calculated through appropriate statistical method was enrolled for this study. The number was determined by a standard normal deviation set at 1.96 which corresponds to $95 \%$ confidence level and a margin of sampling error acceptable set at $5 \%$.

\section{Research instrument}

A well structured self-administered questionnaire organized to elicit information on the following issues:

1. sociodemographic information (age, type of family, gravidal status, educational background, occupation and marital status).

2. Knowledge of HIV/AIDS

3. Attitude toward PLWHA.

The questionnaire was pretested for comprehensibility, appropriateness of language and sensitivity of questions including average duration of administration. It was administered in English Language during clinic sessions with the assistance of final year pharmacy students who were trained on questionnaire administration, technique and retrieval. We had at least one pharmacist representative of the three major languages: Ibo, Hausa and Yoruba who administered the questionnaire. This was necessitated in order to overcome these language barriers.

\section{Ethical issues}

Consent to administer the questionnaire was obtained from the appropriate authorities within the hospital. All pregnant women who came for ante-natal booking care in the hospital during the study period were eligible for the survey except few who refused to be administered the questionnaire. The nature of the study was explained to them and their consent obtained while maintaining maximum confidentiality of information by excluding the names of the respondents or any information that could be linked to anybody. Data collection covered a period of three and half months.

\section{Inclusion criteria}

Potential participants were pregnant women attending antenatal clinic in Olabisi Onabanjo University Teaching Hospital, Sagamu.

\section{Exclusion criteria}

Non-pregnant women, pregnant women not attending OOUTH, Sagamu and all men.

\section{Data analysis}

The data was analyzed using SPSS package version 13.0. Descriptive analyses of frequencies and percentages were generated for all the variables except where specified. The association between the dependent variables was determined.

\section{RESULTS}

The age range of the respondents was 20-59 years. Age range 30-39 years accounted for the highest percentage $(53.1 \%)$ while the age range 50-59 years accounted for $0.5 \%$. Majority (76.7\%) were of monogamous family. While $63 \%$ had tertiary education and above, $29.3 \%$ had secondary, $6.5 \%$ primary and a minor percentage $(1.2 \%)$ had no formal education. The respondents who were first, second, third, fourth or more gravida were $32 \%, 29.5 \%, 18.6 \%$ and $19.9 \%$ respectively. They were mainly business professionals 
(36\%), civil servants $(34.2 \%)$ and majority (94\%) live with their husbands (Table 1).

\section{Respondent's knowledge about HIV/AIDS Causative organism of HIV/AIDS}

Respondents with tertiary educational level had the major percentage $(89 \%)$ of those who indicated that HIV/AIDS is caused by virus, as compared with secondary level $(59.3 \%)$, primary level $(61.5 \%)$ and no formal education (20\%) (Table 2).

\section{Modes of HIV/AIDS prevention}

Respondents with tertiary educational level had the highest percentage on the modes of HIV/AIDS prevention when compared to other educational levels with the following responses given in this order by tertiary, secondary, primary and those with no formal education respectively: avoid causal sex $(77.6 \%, 44.1 \%, 42.3 \%, 20 \%)$, avoid sex with HIV infected persons $(70.9 \%, 44.1 \%, 57.7 \%$, $20 \%)$, not sharing injection needle $(83.5 \%$, $50 \%, 46.2 \%, 40 \%)$, reject transfusion of unscrened blood $(76 \%, 42.4 \%, 42.3 \%, 60 \%)$ and abstain from penetrative sex $(37.4 \%$, $13.6 \%, 11.5 \%, 0.0 \%$ ) (Table 3a et b).

Knowledge of HIV transmission from mother to child

On the over all, tertiary educational level respondents had the highest knowledge of mother to child transmission of HIV/AIDS as indicated by the reponses given respectively by tertiary, secondary, primary and those with no formal education: during pregnancy $(57.1 \%, 55.9 \%, 26.9 \%, 60 \%)$, during delivery $(43.3 \%, 22.9 \%, 11.5 \%, 0.0 \%)$ and during breast feeding $(52 \%, 38.1 \%$, 42.3\%, 40\%) (Table 4).

\section{Attitude of respondents toward people living with HIV/AIDS}

With regard to attitude, respondents with tertiary educational level had a better receptive attitude compared to others although those with no formal education were more willing to buy fresh vegetables from HIV positive food sellers. These can be seen from the responses indicated by tertiary respondents as compared to those with no formal education respectively: willing to buy fresh vegetables from HIV positive food sellers $(52.4 \%, 41.5 \%, 50 \%, 60 \%)$, willing to allow an HIV positive trader to trade in the market $(72.4 \%, 51.7 \%, 57.7 \%, 60 \%)$, willing to care for a HIV positive family member $(87 \%$, $82.2 \%, 73.1 \%, 80 \%)$, willingness to employ a healthy looking HIV positive person $(56.3 \%$, $45.8 \%, 46.2 \%, 40 \%$ ) (Table 5).

Table 1: Socio-demographic characteristics of respondents.

\begin{tabular}{lcc}
\hline Age (years) & Frequency & Percentage $(\%)$ \\
\hline $20-29$ & 151 & 37.5 \\
$30-39$ & 214 & 53.1 \\
$40-49$ & 36 & 8.9 \\
$50-59$ & 2 & 0.5 \\
Total & 403 & 100 \\
& & \\
Type of Family & & \\
Monogamous & 309 & 76.7 \\
Polygamous & 94 & 23.3 \\
Total & 403 & 100 \\
Gravida & & \\
First & 129 & 32.0 \\
Second & 119 & 29.5
\end{tabular}




\begin{tabular}{lcc} 
Third & 75 & 18.6 \\
Fourth and above & 80 & 19.9 \\
Total & 403 & 100 \\
Educational Background & & \\
No formal education & 5 & 1.2 \\
Primary & 26 & 6.5 \\
Secondary & 118 & 29.3 \\
Tertiary and above & 254 & 63.0 \\
Total & 403 & 100 \\
Occupation & & \\
Civil servant & 138 & 34.2 \\
Health professional & 22 & 5.5 \\
Business professional & 145 & 36.0 \\
Student & 47 & 11.7 \\
Unemployed & 36 & 8.9 \\
Any other (specify) & 15 & 3.7 \\
Total & 403 & 100 \\
Marital Status & & \\
Live together with husband & 379 & 94.0 \\
Separated & 15 & 3.7 \\
Single parent & 9 & 2.2 \\
Total & 403 & 100 \\
\hline
\end{tabular}

Table 2: Knowledge of the cause of HIV/AIDS with educational level of the respondents.

\begin{tabular}{|c|c|c|c|c|c|}
\hline Educational & Bacteria & $\begin{array}{l}\text { Evilspirit/ } \\
\text { witchcraft }\end{array}$ & Virus & Fungi & $\begin{array}{c}\text { Excessive } \\
\text { drinking of } \\
\text { alcohol }\end{array}$ \\
\hline $\begin{array}{c}\text { No formal } \\
\text { education } \mathrm{n}=5 \\
(\%)\end{array}$ & $1(20)$ & $3(60)$ & $1(20)$ & $0(0)$ & $0(0.0)$ \\
\hline $\begin{array}{c}\text { Primary in }=26 \\
(\%)\end{array}$ & $4(15.4)$ & $3(11.5)$ & $\begin{array}{c}16 \\
(61.5)\end{array}$ & $2(7.7)$ & $1(3.8)$ \\
\hline $\begin{array}{c}\text { Secondary } \mathrm{n}=118 \\
(\%)\end{array}$ & $\begin{array}{c}32 \\
(27.1)\end{array}$ & $7(5.9)$ & $70(59.3)$ & $8(6.8)$ & $1(0.8)$ \\
\hline $\begin{array}{c}\text { Tertiary and } \\
\text { above } n=254(\%)\end{array}$ & $25(9.8)$ & $2(0.8)$ & $226(89)$ & $1(0.4)$ & $0(0.0)$ \\
\hline
\end{tabular}


W. A. OJIEABU et al. / Int. J. Biol. Chem. Sci. 6(4): 1582-1592, 2012

Table 3a: Comparison of educational level with knowledge of prevention of HIV/AIDS among the respondents.

\begin{tabular}{lccccrr}
\hline Educational level & A & B & C & D & E & F \\
\hline No formal education $\mathrm{n}=5(\%)$ & $1(20)$ & $3(60)$ & $1(20)$ & $3(60)$ & $2(40)$ & $0(0.0)$ \\
Primary $\mathrm{n}=26(\%)$ & $11(42.3)$ & $13(50)$ & $15(57.7)$ & $7(26.9)$ & $12(46.2)$ & $4(15.4)$ \\
Secondary $\mathrm{n}=118(\%)$ & $52(44.1)$ & $66(56)$ & $52(44.1)$ & $39(33.1)$ & $59(50)$ & $20(17)$ \\
Tertiary \&above $\mathrm{n}=254(\%)$ & $197(77.6)$ & $175(68.9)$ & $180(70.9)$ & $157(61.8)$ & $212(83.5)$ & $51(20.1)$ \\
& & & & & \\
\hline
\end{tabular}

$\mathrm{A}=$ Avoid causal sex, $\mathrm{B}=$ Use condom during sex, $\mathrm{C}=$ Avoid sex with HIV infected person, $\mathrm{D}=$ Avoid sex with prostitutes, $\mathrm{E}=$ Not sharing injection needle, $F=$ Avoid contact with HIV infected person.

Table 3b: Comparison of educational level with knowledge of prevention of HIV/AIDS among the respondents (contd).

\begin{tabular}{lcccccc}
\hline Educational level & A & B & C & D & E & F \\
\hline No formal education $\mathrm{n}=5(\%)$ & $0(0.0)$ & $0(0.0)$ & $2(40)$ & $3(60)$ & $0(0.0)$ & $1(20)$ \\
Primary $\mathrm{n}=26(\%)$ & $9(34.6)$ & $1(3.8)$ & $6(23.1)$ & $11(42.3)$ & $3(11.5)$ & $1(3.8)$ \\
Secondary $\mathrm{n}=118(\%)$ & $30(25.4)$ & $13(11)$ & $29(24.6)$ & $50(42.4)$ & $16(13.6)$ & $2(1.7)$ \\
Tertiary \&above $\mathrm{n}=254(\%)$ & $141(55.5)$ & $78(30.7$ & $13052.2)$ & $193(76)$ & $95(37.4)$ & $5(2)$ \\
\hline
\end{tabular}

A = Have sex only with a faithful uninfected partner, $\mathrm{B}=$ Avoid anal sex, $\mathrm{C}=$ Avoid sex before marriage, $\mathrm{D}=$ Reject unscreened blood transfusion, $\mathrm{E}=$ Abstain from penetrative sex, $\mathrm{F}=$ No way a person can avoid HIV infection. 
W. A. OJIEABU et al. / Int. J. Biol. Chem. Sci. 6(4): 1582-1592, 2012

Table 4: Comparison of educational level with knowledge of HIV transmission from mother to child.

\begin{tabular}{lccc}
\hline Educational level & $\begin{array}{c}\text { During } \\
\text { pregnancy }\end{array}$ & $\begin{array}{c}\text { During } \\
\text { delivery }\end{array}$ & $\begin{array}{c}\text { During breast } \\
\text { feeding }\end{array}$ \\
\hline No formal education $\mathrm{n}=5(\%)$ & $3(60)$ & $0(0.0)$ & $2(40)$ \\
Primary $\mathrm{n}=26(\%)$ & $7(26.9)$ & $3(11.5)$ & $11(42.3)$ \\
Secondary $\mathrm{n}=118$ & $66(55.9)$ & $27(22.9)$ & $45(38.1)$ \\
Tertiary and above $\mathrm{n}=254(\%)$ & $145(57.1)$ & $110(43.3)$ & $132(52)$ \\
\hline
\end{tabular}

Table 5: Comparison of educational level with attitude of respondents toward people living with HIV/AIDS

\begin{tabular}{lcccc}
\hline Parameter & $\begin{array}{c}\text { No formal education } \mathbf{n = 5} \\
(\boldsymbol{\%})\end{array}$ & $\begin{array}{c}\text { Primary } \\
\mathbf{n = 2 6}(\boldsymbol{\%})\end{array}$ & $\begin{array}{c}\text { Secondary } \\
(\boldsymbol{\%})\end{array}$ & $\begin{array}{c}\text { Tertiary } \\
\mathbf{n = 2 5 4}(\mathbf{\%})\end{array}$ \\
\hline $\mathrm{AA}$ & Yes 3(60) & $13(50)$ & $49(41.5)$ & $133(52.4)$ \\
& No 2 (40) & $13(50)$ & $69(58.5)$ & $121(47.6)$ \\
$\mathrm{AB}$ & Yes 3(60) & $15(57.7)$ & $61(51.7)$ & $184(72.4)$ \\
& No 2 (40) & $11(42.3)$ & $57(48.3)$ & $70(27.6)$ \\
$\mathrm{AC}$ & Yes 3(60) & $13(50)$ & $70(59.3)$ & $195(76.8)$ \\
& No 2 (40) & $13(50)$ & $48(40.7)$ & $59(23.2)$ \\
$\mathrm{AD}$ & Yes 2(40) & $14(53.8)$ & $76(64.4)$ & $194(76.4)$ \\
& No 3 (60) & $12(46.2)$ & $42(35.6)$ & $60(23.6)$ \\
$\mathrm{AE}$ & Yes 4 (80) & $19(73.1)$ & $97(82.2)$ & $221(87)$ \\
& No 1 (20) & $7(26.9)$ & $21(17.8)$ & $33(13)$ \\
$\mathrm{AF}$ & Yes 4 (80) & $12(46.2)$ & $41(34.7)$ & $118(46.5)$ \\
& No 1(20) & $14(53.8)$ & $77(65.3)$ & $136(53.5)$ \\
$\mathrm{AG}$ & Yes 2(40) & $12(46.2)$ & $54(45.8)$ & $143(56.3)$ \\
& No 3 (60) & $14(53.8)$ & $64(54.2)$ & $111(43.7)$ \\
\hline $\mathrm{AA}=$ Respondent is willing to buy fresh vegetables from HIV positive food seller, AB= Respondent would allow a HIV
\end{tabular}

$\mathrm{AA}=$ Respondent is willing to buy fresh vegetables from HIV positive food seller, $\mathrm{AB}=$ Respondent would allow a HIV an $\mathrm{HIV}$ positive person, $\mathrm{AD}=$ Respondent would be willing to shake the hand of an HIV positive person, $\mathrm{AE}=$ Respondent would be willing to care for a family member who became sick with the AIDS virus, AF= Respondent would want it to remain a secret if a member of her family became infected with the AIDS virus, AG= Respondent is willing to employ a healthy-looking person who is HIV positive. 


\section{DISCUSSION}

\section{Knowledge of HIV/AIDS}

The present study aimed to assess impact of educational status on HIV/AIDS knowledge and attitudes among pregnant women attending a University teaching hospital, in Nigeria.

The tertiary respondents had the highest HIV/AIDS knowledge, preventive modes and better attitude across board. A similar study (Negi et al., 2006) also reported that higher educational and socioeconomic status of pregnant women were associated with increase in awareness towards AIDS. With their high educational background, they can read, hear and understand from television, radio and other sources quality information about basic HIV/AIDS knowledge. Only the tertiary level respondents in our study gave encouraging responses about the ways of prevention of HIV, especially regarding, not sharing of injection needles and syringes and rejection of unscreened blood, which compare with findings of other studies (Hayyawi et al., 2010; Eman and Abdelhai, 2011).

The findings also indicated that the majority of the respondents had an average knowledge of the cause of HIV/AIDS, average receptive attitude toward HIV positive patients. Responses from both tertiary and secondary levels were however better than that obtained in earlier studies (Amira et al., 2009; Ramezani and Malek-Afzali, 2008). The respondents obtained an over all below average knowledge of routes of HIV transmission from mother to child which is consistent with some similar work in the country (Ezegwui et al., 2005) and in other countries like Uganda and Tanzania (Harms et al., 2003) although knowledge of mother to child transmission during breast feeding was better than that obtained among nursing groups (Eman and Abdelhai, 2011) before their educational intervention on the study groups.

Knowledge of the cause of HIV/AIDS was very poor among the respondents with no formal education with as high as $60 \%$ indicating that AIDS could be caused by evil spirit/witchcraft which is consistent with another study (Amira et al., 2009) but they had a higher knowledge than the other two levels in areas like avoid sex with prostitutes and reject unscreened blood transfusion which also compares with the result obtained by (Negi et al., 2006) where the higher educational levels could not also favourably compare with the illiterates in the areas of avoid sex with HIV positive persons and prostitutes and not sharing injection needle and reject unscreened blood transfusion. They also had a better attitude in willing to buy fresh vegetables from HIV positive food seller, to allow a HIV positive trader but not sick to continue to trade in the market, and to sit in the bus/church near an HIV positive person than the primary and secondary levels.

Accurate knowledge regarding possible routes of transmission is not only critical for decreasing the infection rate, it is also important to dispel persistent myths as partial knowledge can further perpetuate the risk of infection (Babakian et al., 2004). Poor knowledge and misconceptions about HIV/AIDS are key factors in people's lack of efforts at prevention and it has been shown that people need a solid factual understanding of HIV and its transmission, access to relevant services and the confidence and social power to initiate and sustain behaviour change in order to prevent the spread of HIV/AIDS (Rao and Weiss, 1993).

\section{Attitude}

The respondents' attitude toward people living with HIV/AIDS can be said to be encouraging as they scored above $50 \%$ in many areas especially where a high willingness to care for a family member who has the AIDS virus cuts across board. This is consistent with earlier work (Tee and Huang, 2009; Amira et al., 2009). It was noticd that respondents with tertiary educational level displayed higher positive attitude toward HIV positive persons when compared with other educational level as majority of them would be willing to interact with them in various non-infective ways. The attitude of 
respondents wanting their family members to keep their HIV status secret was also recorded by other researchers (Tee and Huang, 2009; Amira et al., 2009).

\section{Misconceptions}

There were a lot of misconceptions about the cause of HIV/AIDS, since as high as $27 \%$ of those with secondary education still believed AIDS is caused by bacteria, $60 \%$ of the illiterates believed evilspirit/witchcraft and other smaller percentages of respondents believed fungi and excessive drinking of alcohol can cause the disease. There was also a great misconception on ways a mother could infect the child as respondents' knowledge about them was very low. As high as $80 \%$ of the illiterates wanting to keep it a secret if any members of their family became infected with AIDS virus is also another form of misconception. Avoiding contact with HIV infected person in areas of buying fresh vegetable, sitting in the same bus with HIV positive person, shaking hands, employing HIV positive persons, not wanting to care for a HIV positive family member were all misconceptions about HIV/AIDS recorded against the respondents. This problem of misconception was also recorded in our previous investigation (Ojieabu et al., 2008). Other researchers also found that respondents incorrectly indicated that one could contract AIDS through casual contact (Sadob et al., 2006). These misconceptions have a bearing on stigma, discrimination and voluntary testing as they can impact on people who are infected to not test and hence unknowingly spreading HIV. In a related study (FemiOyewo, 2003), the researcher advocated the power of information, education and communication in prevention and control of HIV/AIDS: the author reported that everybody should be informed on HIV/AIDS.

\section{Conclusion}

The results of the study shed light on HIV knowledge among different educational levels of pregnant women, their prevailing misperceptions regarding HIV/AIDS and their attitude towards PLWHAs. The information gathered from this study can be used to plan education strategies, destroy myths about HIV transmission as well as improve efforts to increase tolerance towards PLWHAs. On the over-all, the respondents showed average levels of HIV/AIDS knowledge and attitudes towards people with HIV/AIDS. A significant positive correlation was found between the educational level and knowledge and with attitudes showing the highest knowledge levels and most positive attitudes towards patients with HIV/AIDS. Education and intervention programs are needed to increase the level of knowledge and awareness of HIV/AIDS among this population. Structured education in the form of health talks which could be delivered at their different educational levels should be targeted at pregnant women during clinic hours.

\section{REFERENCES}

Amira Sidig MD, Alsadig Mahgoub DTPH, Abbashar Hussein MD. 2009. A study of knowledge, attitude, practice towards HIV/AIDS and Prevalence of HIV/AIDS among women tea sellers in Khartoum State. Sudanese Journal of Public Health, 4(1): 214-224.

Babakian T, Freier MC, Hopkins GL, Diclemente R, Mcbride D, Riggs $\mathrm{M}$. 2004. An assessment of HIV/ AIDS risk in higher education students in Yerevan, Armenia. AIDS and Behaviour, 8(1): 4761.

Cindy D, Miriam N, Shui fun F, Fiona C, Law SW. 1998. Knowledge, attitudes and behaviour related to HIV and AIDS among Chinese adolescents in Hong Kong. Journal of Adolescents Health, 21: 657-665.

Taher E, Abdelhai R. 2011. Nurses' knowledge, perceptions and attitudes towards HIV/AIDS: Effects of a health education intervention on two nursing groups in Cairo University, Egypt. Journal of Public Health and Epidemiology, 3(4): 144-154. 
Ezegwui HU, Ikeme AC, Onwasigwe CN. 2005. Attitude of antenatal patients in Enugu towards HIV screening. Trop. J. Obstet. Gynecol., 22(2): 156-158.

Fawole IO, Asuzu MC, Oduntan SO, Brieger WR. 1999. A school based AIDS education programme for secondary school students in Nigeria: A review of effectiveness. Health Education Research Theory and Practice, 14(5): 675-683.

Femi-Oyewo. 2003. Information, Education and Comunication in the Prevention and Control of HIV/AIDS. West Afr. J. Pharm., 17(1): 25- 32.

FMH (Federal Ministry of Health of Nigeria). 2006. National HIV/AIDS and STI Control Program (HAST). The 2005 National Seroprevalence Sentinel Survey. Abuja, FMH/HAST 2006.

FMH (Federal Ministry of Health). 2010. Technical Report on the 2008, National HIV/Syphilis Seroprevalence Sentinel Survey Among Pregnant Women Attending Antenatal Clinics in Nigeria. Department of Public Health National AIDS/STI Control Programme. Abuja, Nigeria.

Garcia-Calleja JM, Gouws E, Ghys PD. 2006. National population based of HIV Prevalence surveys in sub-Saharan Africa: results and implications for HIV and AIDS estimates. Sexually Transmitted Infections, 82(3): iii64-iii70.

Harms G, Mayer A, Karcher H. 2003. Prevention of mother to child transmission of HIV in Kenya, Tanzania, Uganda. Report of Government of Tanzania; PMTCT Project. International Coordination Office. Berlin, Germany, 126.

Hayyawi AH, Al-Marayaty AY, Salman WS, Hamed W. 2010. HIV AIDS knowledge, attitudes and beliefs among a group of Iraqis. $E M H J$, 16(1): 18-23.

Kalichman SC, Rompa D. 2000. Functional health literacy is associated with health status and health-related knowledge in people living with HIV-AIDS. Journal of Acquired Immune Deficiency Syndromes and Human Retrovirology, 25(4): 337344.

Negi KS, Khandpal SD, Ashish Kumar, Manishi Kukreti. 2006. Knowledge, Attitude and Perception about HIV/AIDS among Pregnant Womenin Rural Area of Dehradun JKScience. Journal of Medical Education \& Research, 8(3): 133-138.

NIH. 2003. Pathways Linking Education to Health. RFA-OB-03-001. Washington DC. National Institute for Health.

Ojieabu WA, Erah PO, Okafor NA. 2008. HIV/AIDS knowledge and sexual behaviour. Int. J. Health Res., 1(1): 2737.

Onah HE, Mbah AU, Chukwuka JC, Ikeme AC. 2004. HIV/AIDS awareness and sexual practices among undergraduates in Enugu, Nigeria. Nigerian Postgraduaate Medical Journal, 11(2): 121-125.

Tehrani R, Malek-Afzali FH. 2008. Knowledge, attitudes and practices concerning HIV/AIDS among Iranian atrisk sub-populations. Eastern Mediterranean Health Journal, 14(1): 142-156.

UNAIDS (Joint United Nations Programme on AIDS). 2001. HIV Prevention Needs and Successes: A Tale of Three Countries. An Update on HIV Prevention Success in Senegal, Thailand and Uganda, Geneva.

UNAIDS (Joint United Nations Program on HIV/AIDS). 2006. Report on the globalAIDSepidemic.www.unaids.org/en/ HIV_2006GlobalReport/default.asp.Acce ssed 06/11/11.

UNAIDS (Joint United Nations Programme on HIV/AIDS). 2008. GlobalSummaryof theAIDSEpidemic.10. Availableat:http:// www.unaids.org/en/media/unaids/content assets/dataimport/pub/report/2003 /jc1700_epi_update_2009_en.pdf).

UNAIDS (Joint United Nations Programme on HIV/AIDS). 2009. AIDS epidemic update: Global summary of the AIDS epidemic.

UNAIDS/WHO (Joint United Nations Programme on HIV/AIDS/World Health 
Organization). 2007. AIDS Epidemic Update. UNAIDS, World Health Organization, Geneva.

Rao GG, Weiss E. 1993. Women and AIDS: developing a healthy strategy; Washington DC. International Center for Research on Women, ICRW Policy series, No. 1.

Sadob AE, Fawole AO, Sadoh WE, Oladimeji AO, Sotiloye OS. 2006. Attitude of health-care workers to HIV/AIDS. African Journal of Reproductive Health, 10(1): 39-46.

Schillinger D, Grumbach K, Wang F, Wilson C, Daher C, Leong-Grotz K, Castro C, Bindman AB. 2003. Closing the loop: Physician communication with diabetic patients who have low health literacy. Archives of Internal Medicine, 163(1): 83-90.
Scott TL, Gazmararian JA, Williams MV, Baker DW. 2002. Health literacy and preventive health care use among Medicare enrollees in a managed care organization. Medical Care, 40(5): 395404.

Tee Y, Huang M. 2009. Knowledge of HIV/AIDS and attitudes towards people living with HIV among the general staff of a public university in Malaysia. Journal of Social Aspects of HIV/AIDS, 6(4): 179-186.

World Bank. 2000. World Development Report 1999/2000. Entering the $21^{\text {st }}$ Century: The Changing Development Landscape. Oxford University Press: New York, USA. 